\title{
The neuroscience of time and number: untying the Gordian knot
}

\author{
Cindy Lustig* \\ Department of Psychology, University of Michigan, Ann Arbor, MI, USA \\ *Correspondence: clustig@umich.edu
}

Many aspects of the neuroscience of time and number (NEUTIN), as well as its associated psychophysics, have objective, absolute qualities reminiscent of Newtonian physics. For example, both time and number representations have been hypothesized to be based on the absolute value of a pulse-accumulation process generated by a neural pacemaker whose temporal integration is linear with the duration and/ or number of events (Gibbon et al., 1984; Buhusi and Meck, 2005; Allman et al., 2011). Moreover, it has been shown that a single "count" within such a pacemaker/accumulator equals a fixed amount of time (e.g., $200 \mathrm{~ms}$ ). This finding suggests that "pulses" have a uniform size and serve as a common currency for both time and number as long as the pulse-accumulation process can be operated simultaneously in "event" (count) or "run" (time) modes (Meck and Church, 1983; Meck et al., 1985; Meck, 1997; Breukelaar and Dalrymple-Alford, 1998; Roberts et al., 2000; Brannon and Roitman, 2003; Cordes et al., 2007; Roitman et al., 2007). On the other hand, our experience of time and number evokes another well-known characteristic of physics, relativity theory. This aspect is captured by the scalar property: Temporal and numerical judgments are based on the proportional relationships among the durations being timed and/or the objects or events being counted (Gibbon, 1977; Gibbon et al., 1984; Brannon et al., 2001, 2008; Cheng and Meck, 2007; Buhusi and Meck, 2009a,b).

Information processing models of time and number magnitude describe the scalar property as deriving from cognitive processes such as attention, short-term memory, and reference memory (e.g., the mode-control model of counting and timing; Meck and Church, 1983; Meck et al., 1985). Distortions in numerical and temporal cognition occur in neurological and psychiatric conditions that disrupt these processes (e.g., attention deficit hyperactivity disorder, autism, dyscalculia, Parkinson's disease, and schizophrenia) - see Allman and Meck (2011). However, our understanding of the mechanisms underlying NEUTIN and their specific relations to the brain mechanisms underlying other aspects of cognitive processing remains in its infancy.

One barrier to understanding the intricate, intertwined nature of the relations among temporal, numerical, and other aspects of cognitive processing is that researchers have often adopted an Alexandrian solution - that is, divided these aspects into different fields of study. This has led to a lack of consistent agreement on terminology, creating further obstacles to a unified understanding (Paule et al., 1999; Meck and Benson, 2002; Buhusi and Meck, 2005; Meck, 2005; Meck et al., 2008; Coull et al., 2011). There is also a need for technological advances to improve the spatial and, especially critical in this context, temporal resolution of current neuroimaging methods. However, if these efforts are undertaken, the exploration of how the brain performs temporal integration across multiple time scales is expected to be among the premier topics to unite systems, cellular, computational, and cognitive neuroscience over the next decade (Buonomano, 2007).

Questions concerning the impact of development, sensory modality, sleepdependent memory consolidation, stimulus field/whole-body motion, and genetic predispositions toward increased/decreased neurotransmitter activities of dopamine, glutamate, and serotonin systems in cortico-striatal circuits will be important components in future studies of numerical and temporal cognition (Libertus and Brannon, 2009; Dehaene and Brannon, 2010; Sysoeva et al., 2010; Agostino et al., 2011; Wiener et al., 2011). Meanwhile several theoretical and empirical developments promise a more integrated view. In particular, we have suggested that the identity properties of an item (color, shape, size, location, etc.) may be coded by which cortical neurons are firing while temporal properties are coded by the oscillatory properties of that firing (Lustig et al., 2005). Attention serves to modulate and maintain the integrity of this representation, and striatal neurons act as "coincidence detectors" first encoding and then responding to behaviorally relevant patterns of identity and oscillatory inputs. This approach brings together featurebased views of representations in shortand long-term memory (e.g., Oberauer and Kliegl, 2006; see Jonides et al., 2008; Lustig et al., 2009 for discussion) with views that emphasize oscillatory processes and the detection of specific oscillatory patterns for working memory and timing (e.g., Matell and Meck, 2004; Hazy et al., 2006).

Recent findings from Harrington et al. (2010) are interesting from this perspective. Cortico-striatal activation patterns differed at encoding depending on whether participants attended to the pitch or the duration of a tone; in particular, the striatum was especially active during duration encoding, possibly reflecting its role in integrating oscillations across cycles to represent the passage of time (Matell and Meck, 2004; Meck et al., 2008; Allman and Meck, 2011; Harrington et al., 2011a,b; Portugal et al., 2011). However, during retention, striatal activation was equivalent for the two stimulus classes (and greater than a control task), consistent with a striatal role in modulating thalamocortical structures to recurrently maintain the activation patterns associated with relevant stimuli. Another study (Manning et al., 2011) found direct evidence for the role of oscillations in encoding temporal-order information using intercranial recording methods. When patients recalled items they had previously studied, not only were oscillatory patterns present at encoding recapitulated, but the similarity between the oscillatory patterns associated with different items at retrieval varied linearly with the distance between those items at encoding. In addition, those patients that had stronger reinstatement patterns in neural oscillations 
were also more likely to show temporal clustering in their behavioral recall. Interest in fMRI and EEG measures of oscillatory activity in both resting-state and task-oriented neural networks is also rising (e.g., Laufs et al., 2003; Achard et al., 2006) and presents an exciting opportunity for integration with NEUTIN.

The translational impetus to further integrate NEUTIN with other aspects of basic and cognitive neuroscience is compelling. First, accurate estimation of time and number is an essential component of organized behavior (Gallistel and Gibbon, 2000). Disruptions in NEUTIN-related processes are characteristic of and may even be causal in the symptoms of disrupted organization or synchronization present in several neuropsychiatric disorders including dyslexia, aphasia, Parkinson's, and schizophrenia (Eagleman et al., 2005; Wojtecki et al., 2011). Second, timing and counting involve several fundamental cognitive processes (e.g., attention, working memory, long-term memory) for which a long tradition of research has identified dissociable behavioral signatures and neural substrates. These tasks may thus provide, within a single testing session, well-validated measures of multiple cognitive constructs important for diagnosis and treatment. Third, many timing and counting tasks can be administered similarly across species, increasing confidence when extrapolating from animal models to human neurophysiological and cognitive function in the testing and development of drugs for the treatment of schizophrenia, Alzheimer's disease, and other forms of dementia (Meck and Church, 1983; Church et al., 1994; Rakitin et al., 1998; Roitman et al., 2007; Penney et al., 2008; Gu et al., 2011; Meck et al., 2011; Ward et al., 2011). Targeting NEUTIN tasks that have demonstrated cross-species behavioral validity (e.g., Penney et al., 2008) for further development in psychometrics, genetic and pharmacologic manipulations, exploration of neural substrates, and sensitivity to disease models will be an important step in bringing this potential to fruition (for a related example of task development in the control of attention, see Demeter et al., 2008, 2011; Nuechterlein et al., 2009; Luck et al., 2011).

Finally, the ability to use temporal and numerical processing tasks both across species (e.g., Penney et al., 2008) and across the lifespan (Lustig and Meck, 2001, 2011) makes them attractive tools for helping to elucidate the evolutionary and ontogenetic development of cognitive processes. As noted above, basic temporal and numerical processing abilities appear to be present even in relatively simple organisms and in very young children, but NEUTIN-related tasks also seem quite sensitive to irregularities in the functioning of attention and memory. They may therefore be useful in screening children at a very young age to identify those at-risk for difficulties in important educational activities (especially mathematics; Libertus et al., 2011) and even provide a basis for training and intervention (Shaffer et al., 2001; Cosper et al., 2009).

To summarize, temporal and numerical processing is both fundamental and complex. These two domains have often been studied separately from each other, and from other cognitive domains such as attention, memory, and emotion. However, recent developments including a new appreciation of the importance of oscillatory processes in neural function and of the translational value of temporal/numerical processing tasks hold great promise for a better understanding of both NEUTIN perse and how the brain produces organized behavior more generally.

\section{REFERENCES}

Achard, S., Salvador, R., Whitcher, B., Suckling, J., and Bullmore, E. (2006). A resilient, low-frequency, smallworld human brain functional network with highly connected association cortical hubs. J. Neurosci. 26, 63-72.

Agostino, P.V., Golombek, D.A., and Meck, W.H. (2011). Unwinding the molecular basis of interval and circadian timing. Front. Integr. Neurosci. (in press).

Allman, M. J., and Meck, W.H. (2011). Pathophysiological distortions in time perception and timed performance. Brain (in press).

Allman, M. J., Pelphrey, K. A., and Meck, W. H. (2011). Developmental neuroscience of time and number: implications for autism and other neurodevelopmental disabilities. Front. Integr. Neurosci. (in press).

Brannon, E. M., Libertus, M. E., Meck, W. H., and Woldorff, M.G. (2008). Electrophysiological measures of time processing in infant and adult brains: Weber's law holds. J. Cogn. Neurosci. 20, 193-203.

Brannon, E. M., and Roitman, J. D. (2003). "Nonverbal representation of time and number in animals and human infants," in Functional and Neural Mechanisms of Interval Timing, ed. W. H. Meck (Boca Raton: CRC Press), 143-182.

Brannon, E. M., Wusthoff, C. J., Gallistel, C. R., and Gibbon, J. (2001). Subtraction in the pigeon: evidence for a linear subjective number scale. Psychol. Sci. 1, 238-243.
Breukelaar, J. W. C., and Dalrymple-Alford, J. C. (1998). Timing ability and numerical competence in rats. $J$. Exp. Psychol. Anim. Behav. Process. 24, 84-97.

Buhusi, C. V., and Meck, W. H. (2005). What makes us tick? Functional and neural mechanisms of interval timing. Nat. Rev. Neurosci. 6, 755-765.

Buhusi, C. V., and Meck, W. H. (2009a). Relative time sharing: new findings and an extension of the resource allocation model of temporal processing. Philos. Trans. R. Soc. Lond. B Biol. Sci. 364, 1875-1885.

Buhusi, C. V., and Meck, W.H. (2009b). Relativity theory and time perception: single or multiple clocks? PLoS ONE 4, e6268. doi: 10.1371/journal.pone.0006268

Buonomano, D. V. (2007). The biology of time across different scales. Nat. Chem. Biol. 3, 594-597.

Cheng, R. K., and Meck, W. H. (2007). Prenatal choline supplementation increases sensitivity to time by reducing non-scalar sources of variance in adult temporal processing. Brain Res. 1186, 242-254.

Church, R. M., Meck, W. H., and Gibbon, J. (1994). Application of scalar timing theory to individual trials. J. Exp. Psychol. Anim. Behav. Process. 20, 135-155.

Cordes, S., Williams, C. L., and Meck, W. H. (2007). Common representations of abstract quantities. Curr. Dir. Psychol. Sci. 16, 156-161.

Cosper, S. M., Lee, G. P., Peters, S. B., and Bishop, E. (2009). Interactive metronome training in children with attention deficit and developmental coordination disorders. Int. J. Rehabil. Res. 32, 331-336.

Coull, J. T., Cheng, R. K., and Meck, W. H. (2011). Neuroanatomical and neurochemical substrates of timing. Neuropsychopharmacology 36, 3-25.

Dehaene, S., and Brannon, E. M. (2010). Space, time, and number: a Kantian research program. Trends Cogn. Sci. (Regul. Ed.) 14, 517-519.

Demeter, E., Hernandez-Garcia, L., Sarter, M., and Lustig, C. (2011). Challenges to attention: a continuous arterial spin labeling (ASL) study of the effects of distraction on sustained attention. Neuroimage 54, 1518-1529.

Demeter, E., Sarter, M., and Lustig, C. (2008). Rats and humans paying attention: cross-species task development for translational research. Neuropsychology 22, 787-799.

Eagleman, D. M., Tse, P. U., Buonomano, D., Janssen, P., Nobre, A. C., and Holcombe, A. O. (2005). Time and the brain: how subjective time relates to neural time. J. Neurosci. 25, 10369-10371.

Gallistel, C. R., and Gibbon, J. (2000). Time, rate, and conditioning. Psychol. Rev. 107, 289-344.

Gibbon, J. (1977). Scalar expectancy and Weber's law in animal timing. Psychol. Rev. 84, 279-325.

Gibbon, J., Church, R. M., and Meck, W. H. (1984). Scalar timing in memory. Ann. N. Y. Acad. Sci. 423, 52-77.

Gu, B. M., Yin, B., Cheng, R. K., and Meck, W. H. (2011). Quinpirole-induced sensitization to noisy/sparse periodic input: temporal synchronization as a component of obsessive-compulsive disorder. Neuroscience 179, 143-150.

Harrington, D. L., Castillo, G. N., Fong, C. H., and Reed, J. D. (2011a). Neural underpinnings of distortions in the experience of time across senses. Front. Integr. Neurosci. 5:32. doi: 10.3389/fnint.2011.00032

Harrington, D. L., Castillo, G. N., Greenberg, P. A., Song, D. D., Lessig, S., Lee, R. R., and Rao, S. M. (2011b). Neurobehavioral mechanisms of temporal processing deficits in Parkinson's disease. PLoS ONE 6, e17461. doi: 10.1371/journal.pone.0017461 
Harrington, D. L., Zimbelmann, J. L., Hinton, S. C., and Rao, S. M. (2010). Neural modulation of temporal encoding, maintenance, and decision processes. Cereb. Cortex 20, 1274-1285.

Hazy, T. E., Frank, M. J., and O'Reilly, R. C. (2006). Banishing the homunculus: making working memory work. Neuroscience 139, 105-118.

Jonides, J., Lewis, R. L., Nee, D. E., Lustig, C., Berman, M. G., and Moore, K. S. (2008). The mind and brain of short-term memory. Annu. Rev. Psychol. 59, 193-224.

Laufs, H., Krakow, K., Sterzer, P., Eger, E., Beyerle, A., Salek-Haddadi, A., and Kleinschmidt, A. (2003). Electroencephalographic signatures of attentional and cognitive default modes in spontaneous brain activity fluctuations at rest. Proc. Natl. Acad. Sci. U.S.A. 100, 11053-11058.

Libertus, M. E., and Brannon, E. M. (2009). Behavioral and neural basis of number sense in infancy. Curr. Dir. Psychol. Sci. 18, 346-351.

Libertus, M. E., Feigenson, L., and Halberda, J. (2011). Preschool acuity of the approximate number system correlates with school math ability. Dev. Sci. doi: 10.1111/j.1467-7687.2011.01080.x

Luck, S. J., Ford, J. M., Sarter, M., and Lustig, C. (2011). CNTRICS final biomarker selection: control of attention. Schizophr. Bull. doi: 10.1093/schbul/ sbr065

Lustig, C., Berman, M., Nee, D. E., Lewis, R. L., Moore, K. S., and Jonides, J. (2009). "Psychological and neural mechanisms of short-term memory," in Handbook of Neuroscience for the Behavioral Sciences, eds G. G. Bernston and J. T. Caccioppo (Hoboken, NJ: John Wiley \& Sons), 567-585.

Lustig, C., Matell, M. S., and Meck, W. H. (2005). Not "just" a coincidence: frontal-striatal synchronization in working memory and interval timing. Memory 13, 441-448.

Lustig, C., and Meck, W. H. (2001). Paying attention to time as one gets older. Psychol. Sci. 12, 478-484.

Lustig, C., and Meck, W. H. (2011). Modality differences in timing and temporal memory throughout the lifespan. Brain Cogn. (in press).

Manning, J. R., Polyn, S. M., Baltuch, G. H., Litt, B., and Kahana, M. J. (2011). Oscillatory patterns in temporal lobe reveal context reinstatement during memory search. Proc. Natl. Acad. Sci. U.S.A. 108, 12893-12897.
Matell, M. S., and Meck, W. H. (2004). Cortico-striatal circuits and interval timing: coincidence detection of oscillatory processes. Brain Res. Cogn. Brain Res. 21, 139-170.

Meck, W. H. (1997). "Application of a mode-control model of temporal integration to counting and timing behaviour," in Time and Behaviour: Psychological and Neurobiological Analyses, eds C. M. Bradshaw and E. Szabadi (New York: Elsevier), 133-184.

Meck, W.H.(2005). Neuropsychology of timing and time perception. Brain Cogn. 58, 1-8.

Meck, W. H., and Benson, A. M. (2002). Dissecting the brain's internal clock: how frontal-stratial circuitry keeps time and shifts attention. Brain $\operatorname{Cogn}$. 48, 195-211.

Meck, W. H., Cheng, R. K., MacDonald, C. J., Gainetdinov, R. R., Caron, M. G., and Çevik, M. Ö. (2011). Gene-dose dependent effects of methamphetamine on interval timing in dopaminetransporter knockout mice. Neuropharmacology. doi: 10.1016/j.neuropharm.2011.01.042. [Epub ahead of print].

Meck, W. H., and Church, R. M. (1983). A mode-control model of counting and timing processes. J. Exp. Psychol. Anim. Behav. Process. 9, 320-334.

Meck,W.H., Church, R.M., and Gibbon,J. (1985). Temporal integration in duration and number discrimination. J. Exp. Psychol. Anim. Behav. Process. 11, 591-597.

Meck, W. H., Penney, T. B., and Pouthas, V. (2008). Cortico-striatal representation of time in animals and humans. Curr. Opin. Neurobiol. 18, 145-152.

Nuechterlein, K. H., Luck, S. J., Lustig, C., and Sarter, M. (2009). CNTRICS final task selection: control of attention. Schizophr. Bull. 35, 182-196.

Oberauer, K., and Kliegl, R. (2006). A formal model of capacity limits in working memory. J. Mem. Lang. 55, 601-626.

Paule, M. G., Meck, W. H., McMillan, D. E., McClure, G. Y. H., Bateson, M., Popke, E. J., Chelonis, J. J., and Hinton, S. C. (1999). The use of timing behaviors in animals and humans to detect drug and/or toxicant effects. Neurotoxicol. Teratol. 21, 491-502.

Penney, T. B., Gibbon, J., and Meck, W. H. (2008). Categorical scaling of duration bisection in pigeons (Columba livia), mice (Mus musculus), and humans (Homo sapiens). Psychol. Sci. 19, 1103-1109.
Portugal, G. S., Wilson, A. G., and Matell, M. S. (2011). Behavioral sensitivity of temporally modulated striatal neurons. Front. Integr. Neurosci. 5:30. doi: 10.3389/ fnint.2011.00030

Rakitin, B. C., Gibbon, J., Penney, T. B., Malapani, C., Hinton, S. C., and Meck, W. H. (1998). Scalar expectancy theory and peak-interval timing in humans. J. Exp. Psychol. Anim. Behav. Process. 24, 15-33.

Roberts, W. A., Coughlin, R., and Roberts, S. (2000). Pigeons flexibly time or count on cue. Psychol. Sci. 11, 218-222.

Roitman, J. D., Brannon, E. M., Andrews, J. R., and Platt, M. L. (2007). Nonverbal representation of time and number in adults. Acta Psychol. (Amst.) 124, 296-318.

Shaffer, R. J., Jacokes, L. E., Cssily, J. F., Greenspan, S. I., Tuchman, R. F., and Stemmer, P. J. Jr. (2001). Effect of interactive metronome training on children with ADHD. Am. J. Occup. Ther. 55, 155-162.

Sysoeva, O. V., Tonevitsky, A. G., and Wackermann, J. (2010). Genetic determinants of time perception mediated by the serotonergic system. PLOS ONE 5, e12650. doi: 10.1371/journal.pone.0012650

Ward, R. D., Kellendonk, C., Kandel, E. R., and Balsam, P. D. (2011). Timing as a window on cognition in schizophrenia. Neuropharmacology. doi: 10.1016/ j.neuropharm.2011.04.014. [Epub ahead of print].

Wiener, M., Lohoff, F. W., and Coslett, H. B. (2011). Double dissociation of dopamine genes and timing in humans. J. Cogn. Neurosci. 23, 2811-2821.

Wojtecki, L., Elben, S., Timmermann, L., Reck, C., Maarouf, M., Jörgens, S., Ploner, M., Südmeyer, M., Groiss, S., Sturm, V., Niedeggen, M., and Schnitzler, A. (2011). Modulation of human time processing by subthalamic deep brain stimulation. PLoS ONE (in press).

Received: 16 August 2011; accepted: 16 August 2011; published online: 09 September 2011.

Citation: Lustig C (2011) The neuroscience of time and number: untying the Gordian knot. Front. Integr. Neurosci. 5:47. doi: 10.3389/fnint.2011.00047

Copyright $(2011$ Lustig. This is an open-access article subject to a non-exclusive license between the authors and Frontiers Media SA, which permits use, distribution and reproduction in other forums, provided the original authors and source are credited and other Frontiers conditions are complied with. 